Original Article

\title{
BIO-HERBICIDAL EFFICIENCY OF WITHANIA SOMNIFERA AGAINST IMPORTANT HIMALAYAN WEEDS
}

\author{
MAMTA SHARMAa , RUPINDER KAUR', SUNIL PURI ${ }^{b}$ \\ ${ }^{a}$ Faculty of Botany, Shoolini University, Solan (Himachal Pradesh) 173212, India, bDean Academics, Shoolini University, Solan (Himachal \\ Pradesh) 173212, India, cFaculty of Botany, Uttarnchal College of Science and Technology, Dehradoon (UK) 248001, India \\ Email: diamondmamta@gmail.com \\ Received: 16 Aug 2016 Revised and Accepted: 17 Jan 2017
}

\section{ABSTRACT}

Objective: The aim of the study was to evaluate the bioherbicidal activity of Withania somnifera against germination and growth of noxious weeds of Himalaya i.e. Ageratum coenyzoides, Chenopodium album and Achyranthus aspera in a laboratory and foliar spray bioassay which will act as a tool of weed management in the Himalayan region.

Methods: Root, stem and leaf aqueous extract of Withania somnifera at $100 \%$ concentration were applied to determine their effect on the seed germination and seedling growth of tested weeds under laboratory condition. Foliar spray bioassay was carried out by spraying extracts of Withania somnifera on three-month-old seedlings of weeds for two months. Germination and growth of weeds were assessed using growth parameters into account i.e. germination percentage, stem length, root length, fresh weight, dry weight, no of shoot branches and no of root branches.

Results: The results revealed that all the aqueous extracts markedly suppressed germination and seedling growth of $A$. coenyzoides, $C$. album and $A$. aspera. Withania extracts remarkably effected germination, the growth of Ageratum coenyzoides in comparison to other studied weeds. The leaf extract of Withania was more pronounced than stem and root extracts in germination assay. Infoliarspray bioassay, aqueous leaf extracts of $100 \%$ $\mathrm{w} / \mathrm{v}$ concentrations were sprayed on three month old seedlings of weeds at an interval of 5 d. All the aqueous extracts significantly suppressed shoot length, root length, fresh weight and dry weight of Ageratum coenyzoides, Chenopodium album and Achyranthus aspera seedling. In foliar spray bioassay, leaf extract suppressed the stem length, root length, fresh weight, dry weight, no. of root branches and no of shoot branches of studied weeds more commendably than stem and root extract. The suppression of growth parameters could be attributed to the presence of phytochemicals present in the extracts of Withaniasomnifera.

Conclusion: The present study concludes that Withania somnifera contain bio-herbicidal compounds in leaf, stem and root as plant extracts adversely affect weed growth of studied weeds. Henceforth the strategy bio-control of weed is a safe and effective method which could prove a milestone in weed management in Mid-Himalaya.

Keywords: Allelopathy, Weeds, Extract, Herbicidal effect

(C) 2016 The Authors. Published by Innovare Academic Sciences Pvt Ltd. This is an open access article under the CC BY license (http://creativecommons.org/licenses/by/4.0/) DOI: http://dx.doi.org/10.22159/ijpps.2017v9i3.14740

\section{INTRODUCTION}

In Himalayan ecosystem one of the challenging issues is to control weeds which is a threatening problem for plant diversity. Allelopathy is a pragmatic approach for sustainable weed management. Allelopathy is the suppression of one species by another species due to release of chemicals, both negative and positive aspects included in this phenomenon [1]. Every aspect of allelopathy is interlinked with allelochemicals, which are secondary metabolites, produced by the plants as the by-products of their metabolic processes [2]. The higher concentrations of allelechemicals usually inhibit the growth of recipient plants and soil microorganisms or both. These allelochemicals could be extracted from the plants and applied over target weed for getting desirable weed management. Such a herbicidal effect of plants against weeds is less toxic and harmful to ecology. Allelopathic interaction of plants is present need to be used as potentially safe weedicide [3]

The ecosystems infested with weeds show drastic alterations in their structure and function. Weed species which are the part of dynamic ecosystems originate in the natural environment and become a hurdle to the crops $[4,5]$. These weeds have some diagnostic features, such as short seed dormancy period, high rate of seed germination, rapid seedling growth, high reproductive ability, life cycle of a short span, very high environmental plasticity, selfcompatibility, effective and efficient methods of dispersal of propagules, production of different types of novel eco chemicals and tolerance to biotic and abiotic stresses [6], which enable them to grow and survive in varied habitats and inhospitable ecological conditions. As a result of these features, weeds are becoming dominant throughout the world [7], and threaten the native phytodiversity $[8,9]$. Allelopathic chemicals have the potential use as bioherbicides and pesticides. Withania somnifera has shown allelopathic potential against Parthenium hysterophorus [9]. Similarly, the qualitative and quantitative phytochemical studies of crude extract and fractions in Clerodendrum serratum showed the presence of phenolics, flavonoids, saponins, and carbohydrates [8]. The Himalayan region is highly infected with Chenpodium album, Ageratum coenyzoides and Achyranthus aspera which are not only invading Himalayan plant diversity and agricultural crops but also disturbing ecological balances. Therefore, to evaluate the allelochemical potential of Withania somnifera against weeds of the Himalaya, studies were undertaken to see the influence of water extract on Chenopodium album, Achyranthus aspera and Ageratum coenyzoides.

Chenopodium album L. is a fast-growing weedy annual plants of family Chenopodiaceae and is one of the robust and competitive weed found abundantly in winters eason [10]. Achyranthes aspera L. is a perennial herb of the family Amaranthaceae. It is an annual, stiff erect herb, and found commonly as a weed throughout India and is one of the noxious weed of Himachal Pradesh. It is a very common weed of waste places and roadsides in India. The weed bears spiny fruits, which provide a great hindrance in the movement of both humans and animals [11]. Ageratumcoenyzoidesis one such rapidly colonialized invasive alien species of family Asteraceae that has become a troublesome weed over a wide range of ecosystems. It is among the commonest weeds in the Himalayan regions and growing up to the elevation of $2400 \mathrm{~min}$ Himachal Pradesh $[12,13]$; in fact, around $50 \%$ of the area of Himachal Pradesh is said to be infected with this obnoxious weed [7]. 
Withania somnifera (L.) Dunal, a prominent herb of lower Himalaya is commonly known as "Ashwagandha", "Asgandh" and "Winter Cherry". It belongs to Solanaceae family and has 1250 species. Withania somnifera shows the presence of several groups of chemical constituents such as steroidal lactones, alkaloids, flavonoids, tanninetc. Which give the plant material values. At present, more than 12 alkaloids, 40 withanolides (with none, withaferin A, withanolide A, D, H, I, J, K, L, M,

WS-I, P, S, sitoindosides, withanolide $\mathrm{C}$ and with somidioenone) and several sitoindosides (withanolide containing a glucose molecule at carbon 27) have been isolated and reported from aerial parts, roots and berries of Withania species. Withania extract has been found to be effective as bio-herbicide against Parthenium hysterophorus. However, its role against Ageratum coenyzoides, Chenopodium album and Achyranthus aspera has not been tested. The rationale of the study is to to use allelochemicals as a control measure for weed distribution in Himalayan areas. The present study was premeditated to evaluate the herbicidal activity of Withania somnifera using plant extracts against germination and growth of noxious weeds of Himalaya i.e. Ageratum coenyzoides, Chenopodium album and Achyranthus aspera in a laboratory and foliar spray bioassay so as to present a bioherbicidal method for the management of weeds in the Himalayan regions.

\section{MATERIALS AND METHODS}

\section{Study site}

Withania somnifera was grown in the nursery area of Shoolini University. Seeds of weeds for the experiments were collected from the plants in infected sites of Solan District. Plants were identified in BSI, Dehradun and HP University, Shimla (SKS/ZHPU/D. 0. B/-7108).

\section{Chemicals and instrumentation}

Mercuric chloride ( $\mathrm{HgCl} 2)$ was obtained from Sigma-Aldrich (Taufkirchen, Germany). Leachate extract Withania somnifera was tested as bio-herbicide on the prominent weeds i.e. Chenopodium album (Voucher No: SKS/HPU/D. 0. B./-7026) Ageratum coenyzoides (Voucher No: SKS/HPU/D. O. B./-7004) and Achyranthus aspera (Voucher No: SKS/HPU/D. O. B./7000). Seeds of different weeds were collected from heavily infested fields near to Shoolini University. Withania somnifera plants (6 mo old) were excavated from the nursery area and stem, roots and leaves were separated and washed, dried and weighed separately $[10,12]$.

Root/shoot/leaves leachates were prepared taking $50 \mathrm{~g}$ of the plant part and extracted as follow:

(i) Leachate obtained by soaking root, stem and leaves for three different durations $(3,6$ or 9 d).

(ii) Leachates of W. somnifera at two concentrations (50 and 100\% of extract) and distilled water as a control.

To produce the leachates, the leaves/shoot and the root of $50 \mathrm{~g}$ each soaked in $200 \mathrm{ml}$ double-distilled water under aseptic conditions for 3,6 and $9 \mathrm{~d}$ and placed in a conical flask and kept in a refrigerator at $8^{\circ} \mathrm{C}$. The aqueous leachates were filtered through three layers of muslin cloth/cheese cloth to remove debris. The filtrate was then refiltered through one layer of Whatman no.1 filter paper. Leachates of
$100 \%$ and $50 \%$ (leachate prepared by addition of distilled water) concentration were prepared and used for bioassay. Leachate prepared in $100 \%$ concentration and $9 \mathrm{~d}$ treatment were found highly effective on the studied weeds and their effect on studied weeds is presented in this study.

\section{Seed germination assays}

For germination assays, viable seeds of Chenopodium album, Ageratum coenyzoides and Achyranthes aspera were thoroughly washed with tap water to remove dirt and dust, and rinsed with a mild detergent solution for 5-7 $\mathrm{min}$ [10]. The seeds were surfacesterilized with $0.1 \%$ mercuric chloride $(\mathrm{HgCl} 2)$ solution for $10 \mathrm{~min}$ and again washed with sterilized distilled

Water 4-7 times. For each treatment combination, there were three replicates of 10 seeds each. Pre-treated groups were placed in petri dishes on filter paper moistened with distilled water and applied 2 $\mathrm{ml}$ of the relevant leachate (root, shoot and leaves). The relative humidity was 82-84\%. Petri dishes were placed in a growth chamber for observation kept undisturbed for $10 \mathrm{~d}$ at $25^{\circ} \mathrm{C}$. After 10 d observation was made and $2 \mathrm{ml}$ leachate applied to each Petri plate for next $10 \mathrm{~d}$. Treatment was given for 30days.

\section{Foliar spray bioassay}

The impact on seedlings of above-mentioned weeds was assessed by raising seedlings in plastic Pots $(12 \mathrm{~cm} \times 25 \mathrm{~cm})$, containing sterilized soil, sand and FYM (1:1:1) in greenhouse at temperature range with $28 / 18^{\circ} \mathrm{C}$ day/night through a combination of heating $(16 \mathrm{~kW})$ and venting during the day, and heating at night. Fans circulated air continuously to maintain humidity. Two months old seedlings were sprayed with root, shoot and leaf leachates. The regular observation was done at the interval of $5 \mathrm{~d}$ for one month. The experiments were carried out in triplicate. There were 6 single-plantlet replications within each treatment and data were tested $[10,12]$.

The data was analysed statistically as mean values were calculated from measurements of six replicates and the standard error of means were determined. One way and two-way analysis of variance (ANOVA) was applied using Prism software. Tukey's multiple comparison tests was performed at significance level in different treatments.

\section{RESULTS}

\section{Germination}

Chenopodium album, Ageratum coenyzoides and Achyranthus aspera were germinated in the leaf, stem and root extracts of Withania somnifera. Leaves, stem and root extracts delayed seed germination and decreased germination in Chenopodium album seeds. Germination initiated by $3^{\text {rd }}$ day in control (distilled water) while in root and stem extract treatments the seed germination initiated by $4^{\text {th }}$ day. The seeds in the leaf extract treatment initiated germination on 8 th day (fig. 1 and 4). The number of germinated seeds in control is maximum $82 \%$ and lowest in the leaf extract which is $42 \%$. Germination of Achyranthus aspera seeds initiated on $4^{\text {th }}$ day in control whereas $6^{\text {th }}$ day in root and stem extract and $12^{\text {th }}$ day in leaf extract (fig. 1 and 5). Among all applied extracts, leaf extract proved highly effected against control and reduced germination by $28 \%$.

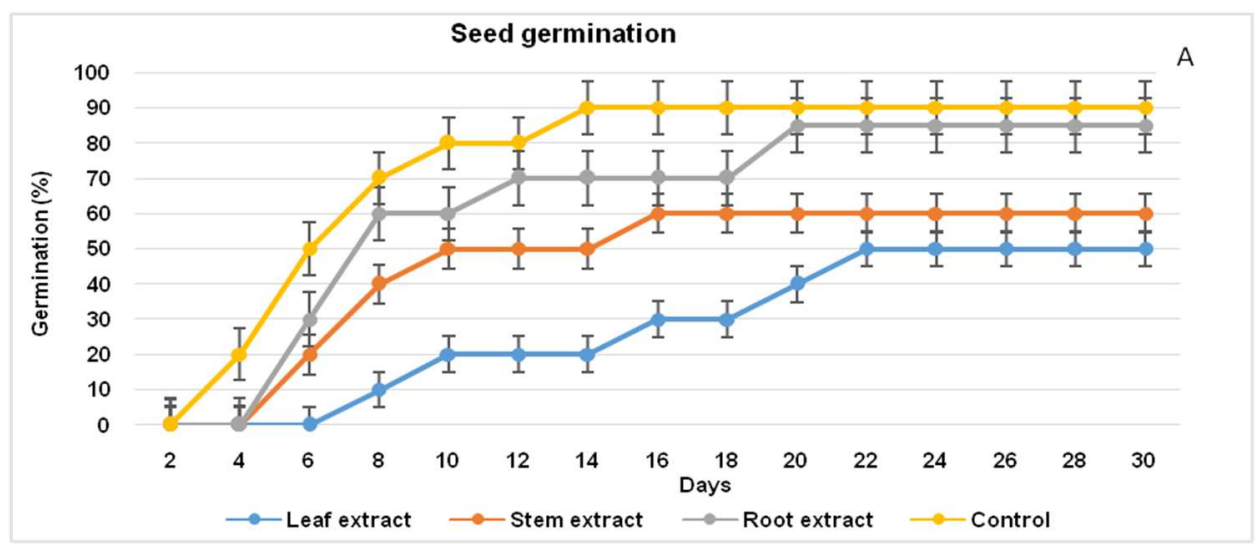




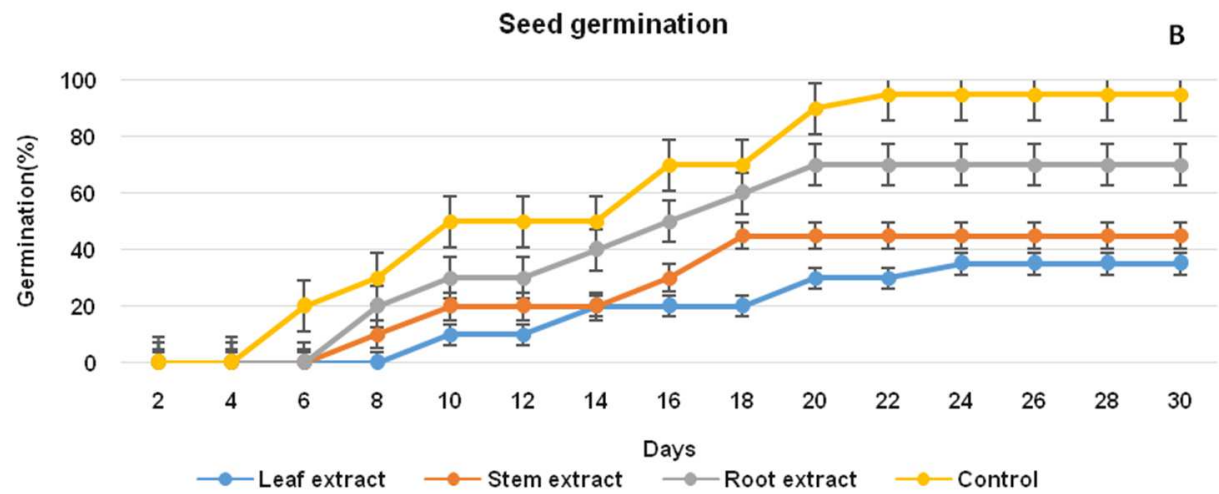

Fig. 1: It shows effect of leaf, stem and root extracts of Withania on seed germination percentage in (A) Chenopodium album and (B) Achyranthus aspera. Values are of mean and S. E., $n=6$

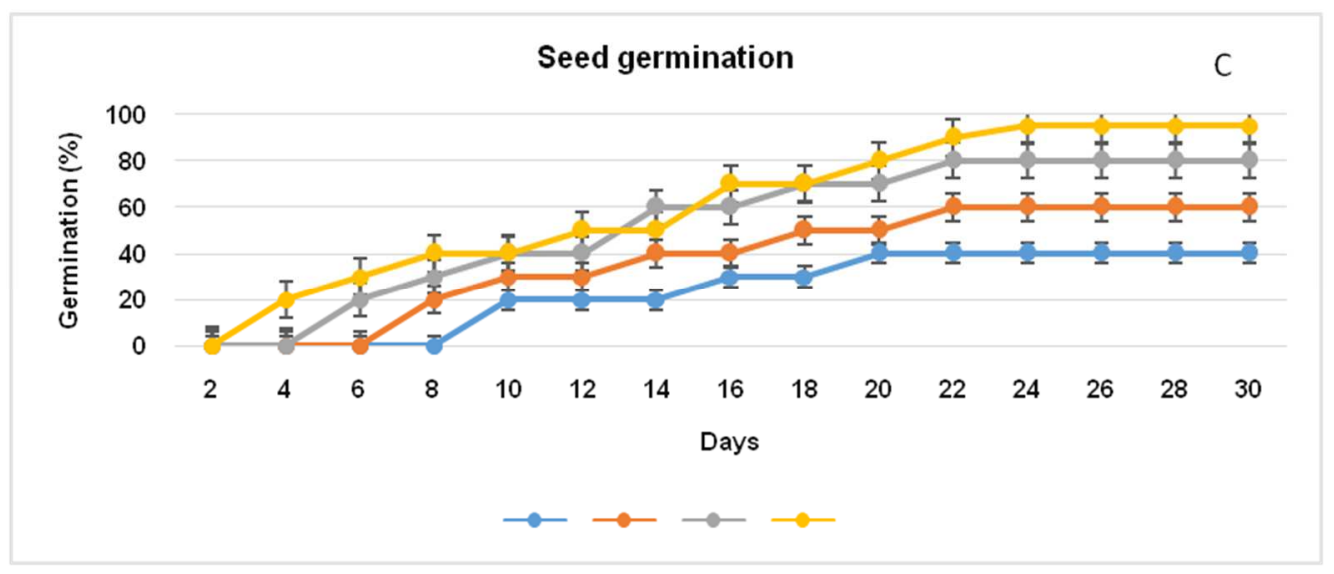

Fig. 2: It shows the effect of leaf, stem and root extracts of Withania on seed germination percentage in Ageratum coenyzoides (C). Values are of mean and $S . E ., n=6$

The seeds of Ageratum coenyzoides showed delayed germination (fig. 2) in all the applied extracts. In control germination initiated by $2^{\text {nd }}$ day whereas it was $4^{\text {th }}$ day in root, $6^{\text {th }}$ day in stem extract and $8^{\text {th }}$ day in leaf extract as shown in fig. 2and6. Leaf extract proved most effective against control $79 \%$ reduction, whereas other stem extract and root extract showed $40 \%$ and $20 \%$ germination respectively. The interpretation revealed that leaf extract adversely affected germination in seeds of all the studied plants. However, root extract was found less effective for inhibition of germination in seeds of different weeds.
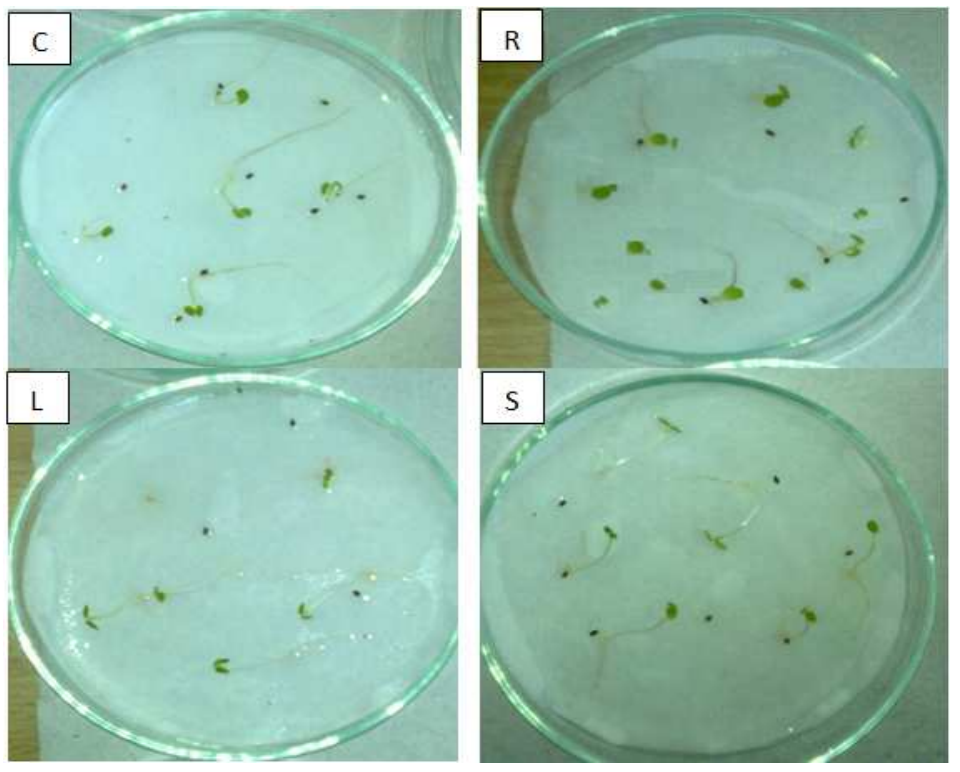

Fig. 3: Shows variation in germination percentage in Chenopodium album treated with leaf (L), stem(S) and root (R) extract of Withania somnifera 


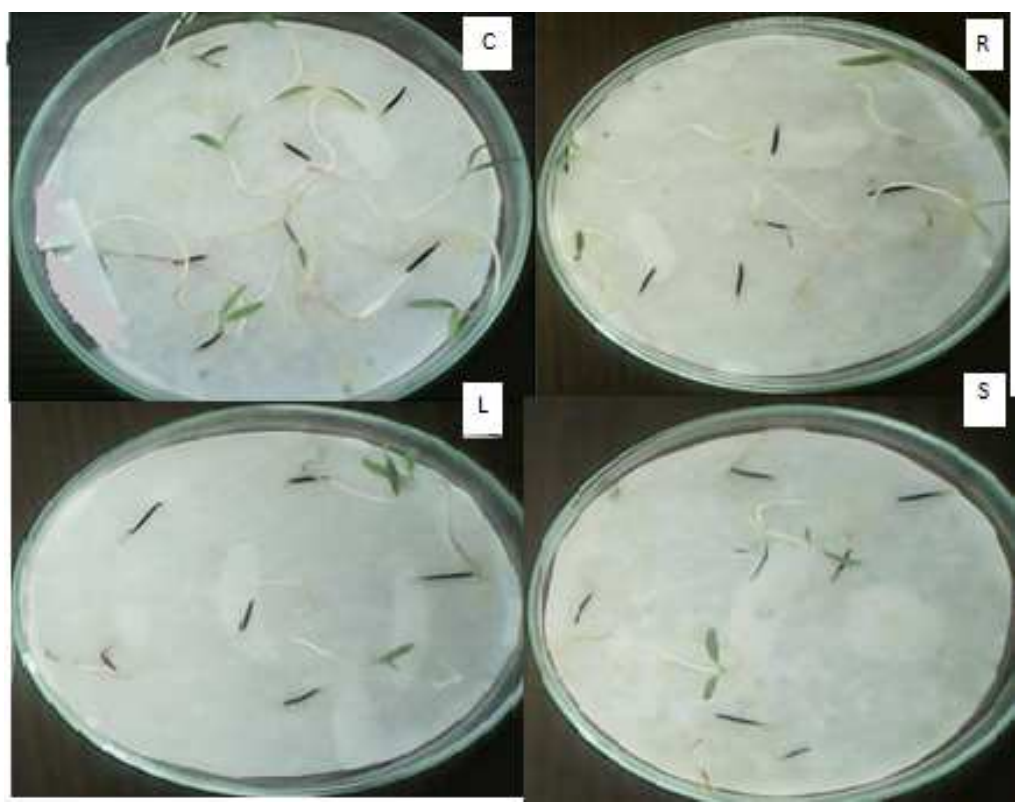

Fig. 4: Shows variation in germination percentage of Ageratum coenyzoides in treated with leaf (L), stem(S) and root (R) extract of Withania somnifera

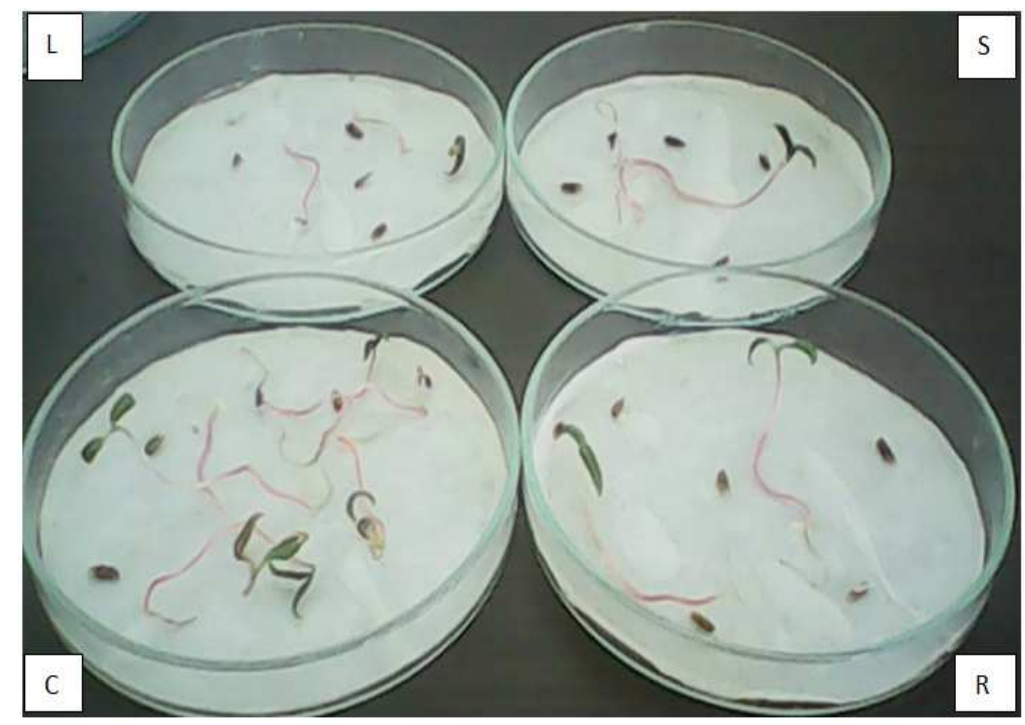

Fig. 5: Shows variation in germination percentage in Ageratum coenyzoides treated with leaf (L), stem (S) and root (R) extract of Withania somnifera
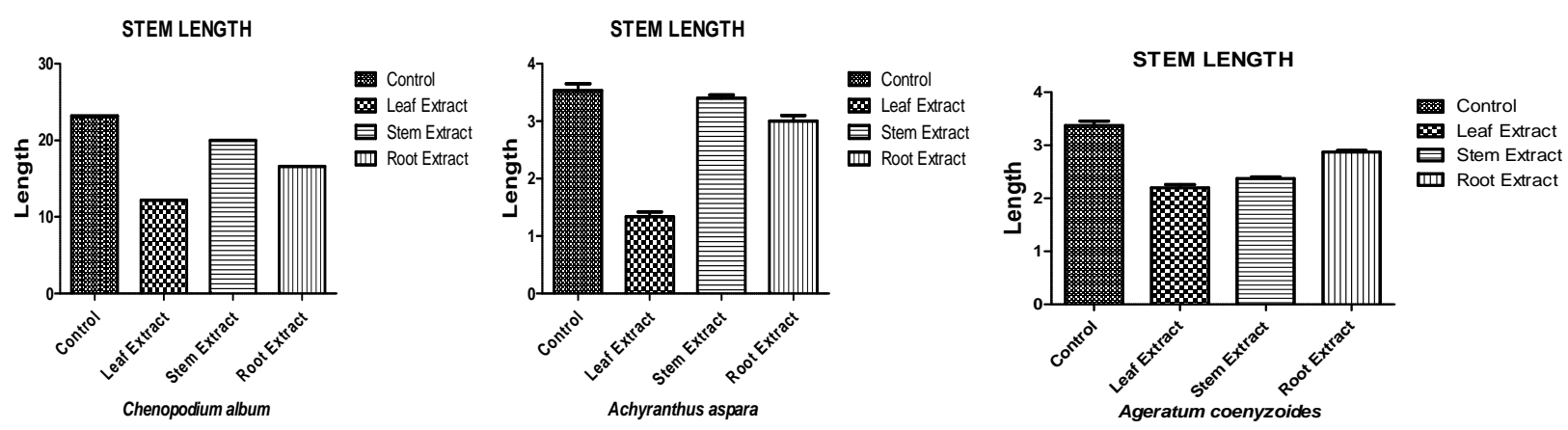

Fig. 6: It shows variation in stem length in different weeds Chenopodium album, Achyranthus asapara and Ageratum coenyzoidus. Values are of mean and SE., $n=6$ 


\section{Seedling shoot length}

The stem length of Chenopodium album was suppressed by all the employed extracts. However, leaf extract proved to be more inhibitory and showed minimum stem length (52\%) followed by stem extract ( $86 \%)$ and root extract (69\%) in comparison to control (fig. 6). Tukey's test of variance interpreted that stem length of plants subjected to leaf extract show non-significant differences from the stem extract subjected plants. A significant difference in the stem length of all other treatment was found. Stem length of Achyranthus aspera also showed reduction upon extract treatment. Minimum stem length was reported that in the plants sprayed with leaf extract (46\%) followed by root extract (85\%) and stem extract (97\%) (fig. 6).

The applied extract treatment suppressed stem length in Ageratum coenyzoides where maximum inhibition was found in the plants treated with leaf extract (44\%) followed by stem extract (36\%) and root extract (15\%) in comparison to control The result is presented in (fig. 6). Statistical analysis and Tukey's test of variance evident that a significant difference was found among all the treatments as shown. The interpretation revealed that effect of Withania extracts on the stem length of target species was significant and leaf extract was highly suppressive against stem length of test species.

\section{Seedling root length}

The root length in Chenopodium album significantly reduced by applied aqueous extracts. Seedlings treated with leaf extract showed a maximum reduction in stem length which is $42 \%$ followed by stem extract (67\%) and root extract (68\%) respectively in comparison to control. Stem extract and root extract showed the approximately similar effect on root length. Measurement of root length in seedlings of Achyranthus aspera revealed that maximum inhibition of root length was reported on treatment with leaf extract (65\%) followed by stem extract (49\%) and stem extract (11\%) in comparison to control (fig. 7). Turkey's test of variance analysed that a significant difference was shown in all the treatment among themselves.
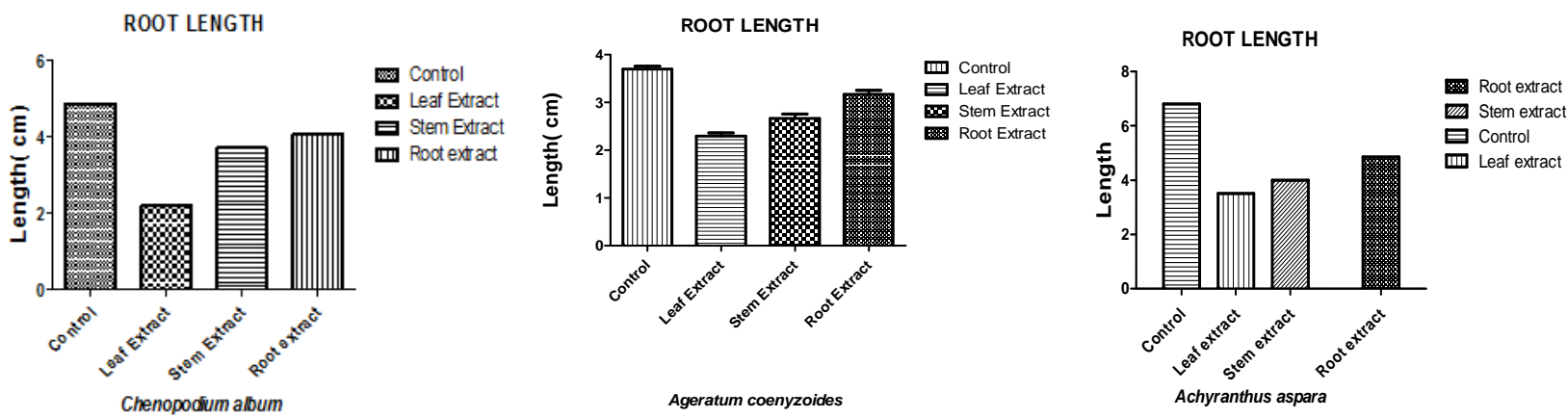

Fig. 7: It shows variation in root length in Chenopodium album, Achyranthus aspera and Ageratum coenyzoides. Values are of mean and standard error, $n=6$

The stem length of Ageratum coenyzoides inhibited by all the applied extracts to a variable extent. Mean values depicted that leaf extracts considerably reduced root length to $62 \%$ followed by stem extract $71 \%$ and root extract $83 \%$ in comparison to control (fig. 7).

\section{Seedling fresh weight}

Fresh weight was highly affected by the leaf, stem and root extract of Withania somnifera in Chenopodium album. Among all the extracts, leaf extract and stem extract reduced fresh weight to a large extent with $57 \%$ and $53 \%$ respectively in comparison to control. However, root extract exerted little effect on fresh weight and reported $76 \%$ fresh weight in comparison to water treated plants (fig. 8). Tukey's multiple comparison tests interpreted that all the treatment showed significant differences among treated and control plants. In early seedlings of Achyranthus aspera, fresh weight reduced in all the extract treatments. It is evident from mean values that minimum fresh weight was reported in the plants treated with leaf extract $(60 \%)$ followed by stem extract $(65 \%)$ and root extract $(83 \%)$ in comparison to control. Fresh weight of Ageratum coenyzoides was severely affected by leaf extract which showed 59\% reduction in comparison to control plants (water treatment). However, stem extract also reduced the fresh weight (50\%) followed by root extract (39 \%). It was concluded from the above interpretation that inhibitory effect of leaf extract of Withania was more severe in Chenopodium album, Achyranthus aspera and Ageratum coenyzoides than other two extracts.
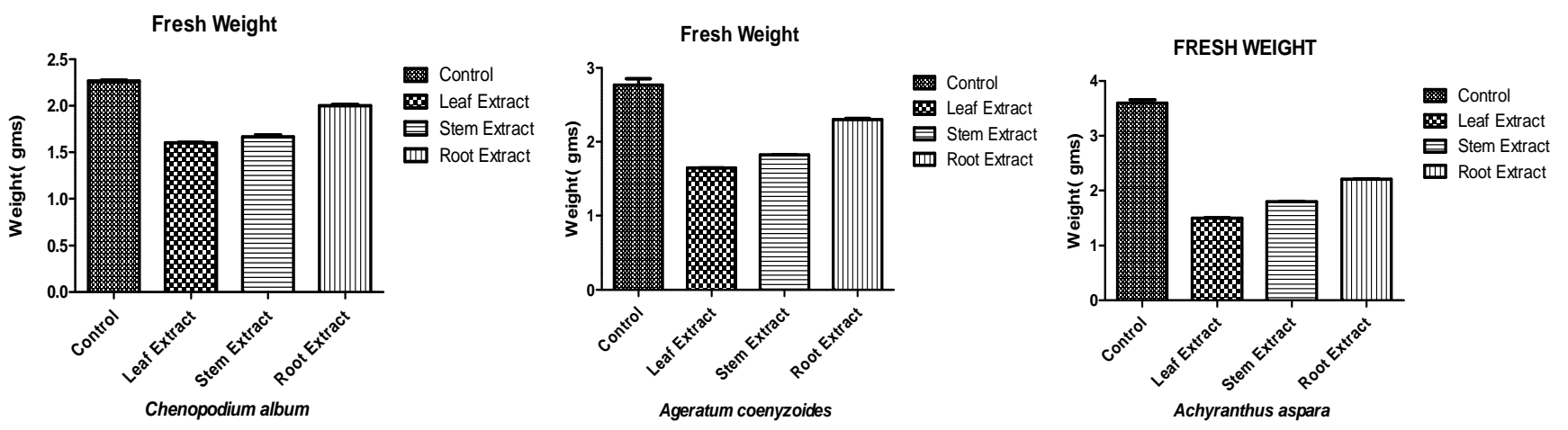

Fig. 8: Shows variation in fresh weight in Chenopodium album, Achyranthus aspera and Ageratum coenyzoides. Values are of mean and $S E, n=6$ 


\section{Total seedling length}

Total plant length in Chenopodium album revealed that minimum inhibition was found in root extract (5\%) followed by stem extract (27\%) and leaf extract (38\%) in comparison to control plants. In Achyranthus aspera extract treated plants showed a significant difference from a plant grown in control condition. It is evident that leaf extract reduced plant length to highest extent (38\%) followed by stem extract (21\%) and then root extract (15\%) in comparison to control plants. The reduction in plant length of extract treated seedlings of Ageratum coenyzoides was reported in comparison to control. The pattern of inhibition of plant length was maximum in leaf extract $(27 \%)$ followed by stem extract $(22 \%)$ and then root extract (5\%) in comparison to control. Tukey's test of variance analysis showed a significant difference in plant length between all the treatments.
PLANT LENGTH

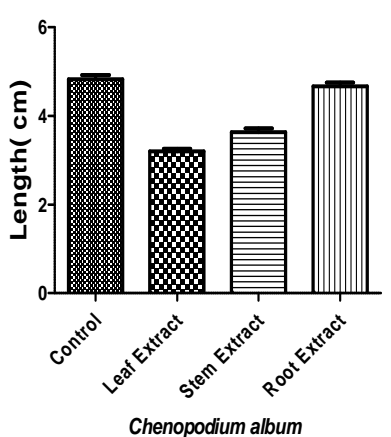

PLANT LENGTH

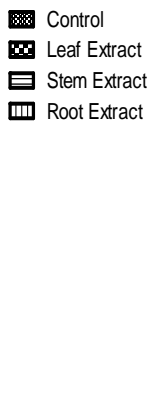

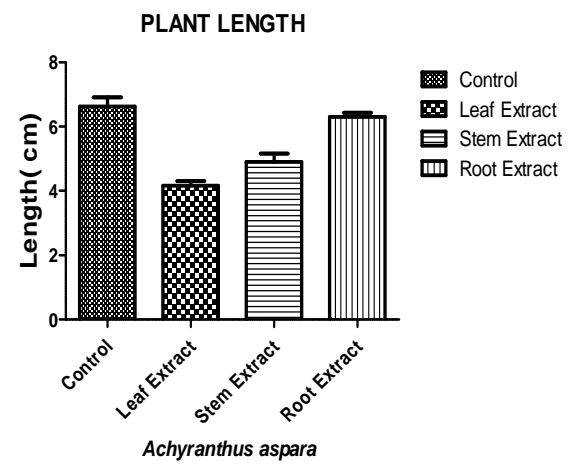

Fig. 9: It shows variation in total plant length in different weeds Chenopodium album, Achyranthus asperaandAgeratum coenyzoides. Values are of mean and $\mathrm{SE}, \mathrm{n}=6$

\section{Growth in foliar spray bioassay}

\section{Stem length}

Foliar spray of Withania adversely affected stem length in treated plants as shown in fig. 1.10. Effect of leaf extract was more pronounced than other extracts as it showed maximum inhibition in stem length i.e. (48\%) whereas (14\%) reduction in root extract and (28\%) in stem extract was recorded.

STEM LENGTH

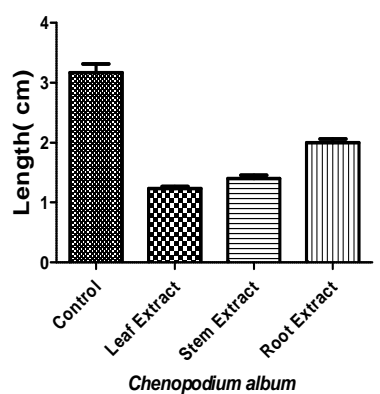

STEM LENGTH

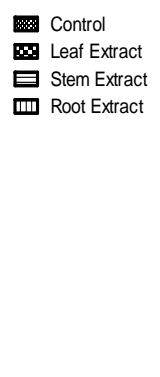

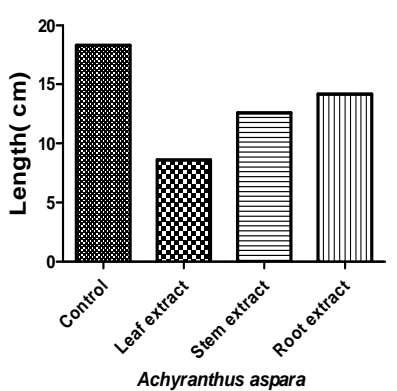

STEM LENGTH

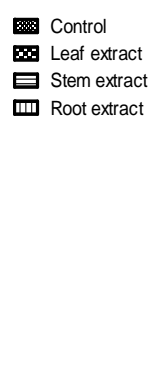

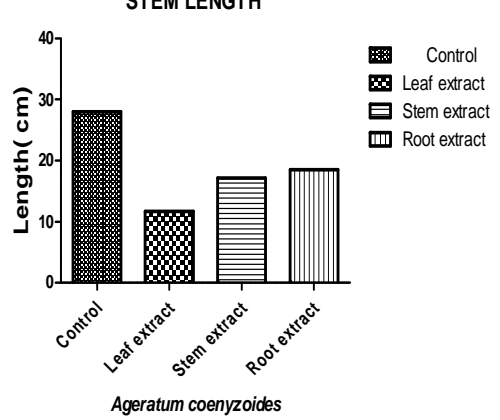

Fig. 10: Shows variation in seedling stem length in different weeds Chenopodium album, Achyranthus asperaandAgeratum coenyzoides. Values are of mean and $S E, n=6$

In Achyranthus aspera spay with aqueous leaf extracts suppressed stem length to a greater extent of $54 \%$ whereas stem length and root length showed $61 \%$ and $66 \%$ reduction respectively in comparison to control. Mean values of stem length of Ageratum coenyzoides revealed that minimum stem length was found in the plants sprayed with leaf extract (39\%) followed by stem extract $(61 \%)$ and root extract $(66 \%)$ in comparison to control. It was evident from above interpretations that leaf extract of Withania on the seedling of Chenopodium album, Achyranthus aspera and Ageratum coenyzoides exerted maximum inhibition whereas minimum inhibition was reported by root extract.

\section{Root length}

Leaf extract showed maximum inhibition by $58 \%$ in root length of Chenopodium album followed by stem extract (33\%) and root extract (32\%) in comparison to control. The analysis was done using one-way ANOVA and Tukey's multiple comparison tests which interpreted that a significant difference was found in different treatment except for leaf extract with stem extract and root extract as given in fig. 11.

The foliar spray of leaf extract reduced root length to a greater extent in Achyranthus aspera is 51\% in comparison to control plants. However, stem extract reduced by $60 \%$ and root extract by $70 \%$ compared to water treated plants.

Measurement of root length in Ageratum coenyzoides revealed that maximum inhibition of root length was found in the plants treated with leaf extract (49\%) followed by stem extract (35\%) and root extract (20\%) in comparison to control. The interpretation of results showed that maximum inhibition of root length in studied plants 
was shown by leaf extract treatment followed by stem extract and

ROOT LENGTH

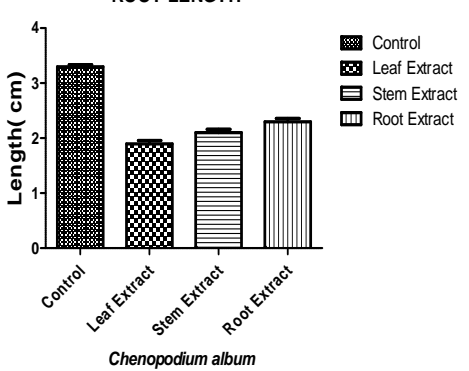

ROOT LENGTH

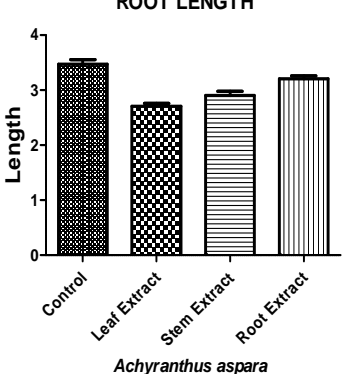

ROOT LENGTH

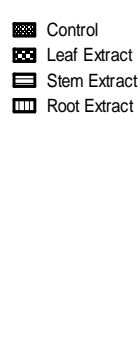

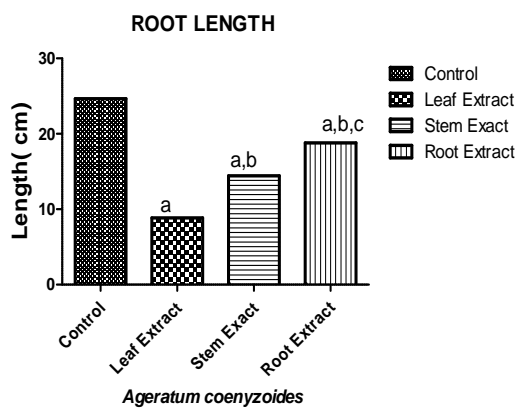

Fig. 11: Shows variation in root length in seedling of different weeds Chenopodium album, Achyranthus aspera and Ageratum coenyzoides. Values are of mean and $S E, n=6$

\section{Fresh weight}

The effect of Withania extracts on fresh weight of Chenopodium album was variable. Leaf extract and stem extract were more inhibitory and showed $42 \%$ stem and $69 \%$ fresh weight in leaf and root extract respectively in comparison to control. Root extract treated plants showed $71 \%$ fresh weight against control plants.
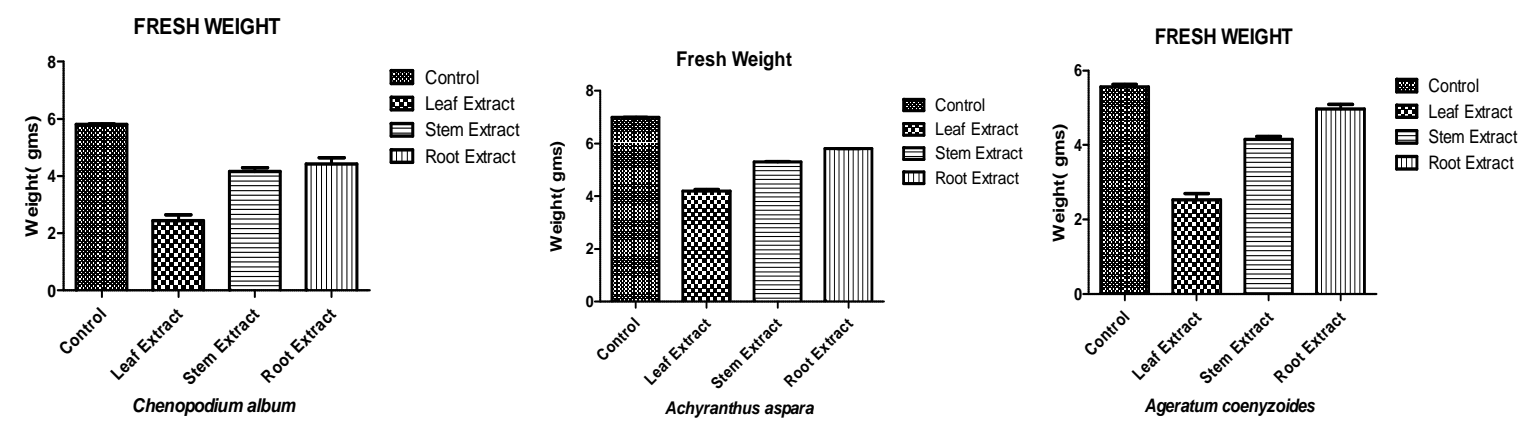

Fig. 12: Shows variation in fresh weight in seedling of different weeds Chenopodium album, Achyranthus aspera and Ageratum coenyzoides

Fresh weight on treatment with leaf extract, stem extract, root extract of Withania to the seedlings of Achyranthus aspera evident that maximum reduction in fresh weight was found in seedlings sprayed with leaf extract ( $42 \%$ ) followed by stem extract $(67 \%)$ and root extract $(68 \%)$ in comparison to control plants. Interpretation of fresh weight in extract treated seedlings of Ageratum coenyzoides showed that leaf extract severely affected the fresh weight by $43 \%$ in comparison to control plants. However, the minimum effect was shown by root extract ( $89 \%$ ) on seedlings of Ageratum coenyzoides against water treated plants.

\section{Dry weight}

Dry weight in Chenopodium album arrested to a greater extent on spray with leaf extract (40\%) followed by stem extract (53\%) and root extract $(65 \%)$ in comparison to control.
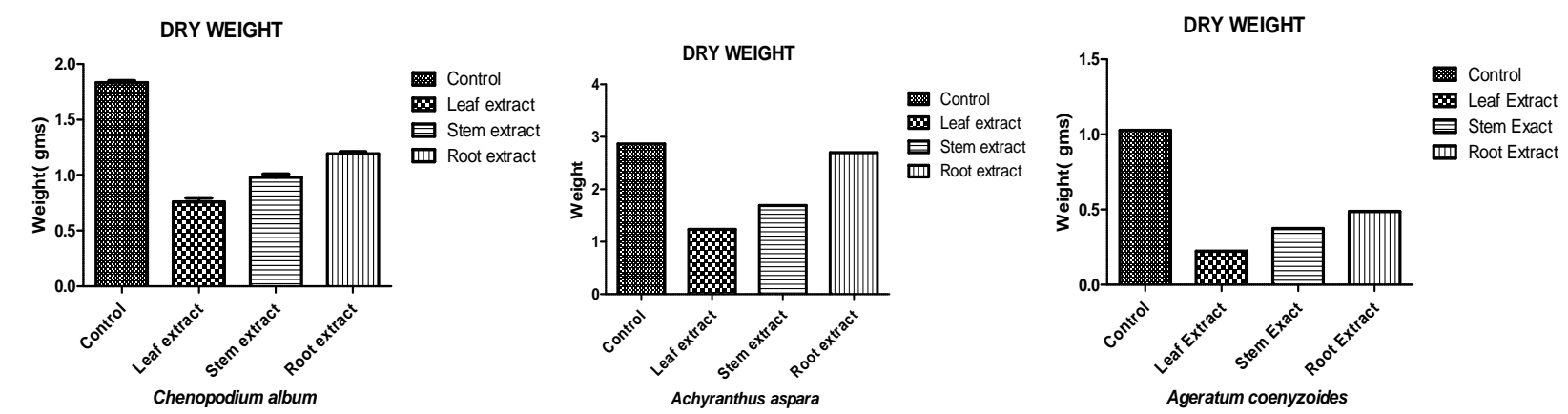

Fig. 13: Variation in dry weight in seedling of different weeds Chenopodium album, Achyranthus aspera and Ageratum coenyzoides. Values are of mean and $S E, n=6$

The dry weight of seedlings of Achyranthus aspera treated with different extract revealed that minimum dry weight was found in the plants sprayed with leaf extract which is only $42 \%$ in comparison to control. However minimum inhibition was shown by root extract where dry weight is $94 \%$. 
It was interpreted from data that dry weight of seedlings treated with leaf, root and stem extract showed inhibition in dry weight. Maximum inhibition was shown by plants sprayed with leaf extract (79\%) followed by stem (64\%) and root extract (62\%) in comparison to control.

\section{Number of shoot branches}

In Chenopodium album mean values of a number of shoot branches revealed that leaf extract shows a minimum number of shoot branches (44\%) then root extract (85\%)and stem extract (88\%) in comparison to control plants.
Analysis of mean and standard error values depicted that seedlings of $A$. aspera treated with leaf extract showed a minimum number of shoot branches which is only $25 \%$ whereas $51 \%$ in stem extract and $87 \%$ in root extract in comparison to control plants. The number of shoot branches of Ageratum coenyzoides treated with leaf extract, stem, and root extract of Withania somnifera was found significantly affected. It was evident from the mean values that minimum plants treated with leaf extract (41\%) showed a minimum number of shoot branches than stem extract $(73 \%)$ and root extract $(86 \%)$ in comparisons to control plants. Tukey's test revealed that a significant difference was found in seedlings treated with leaf extract vs stem extract and root extract vs control.
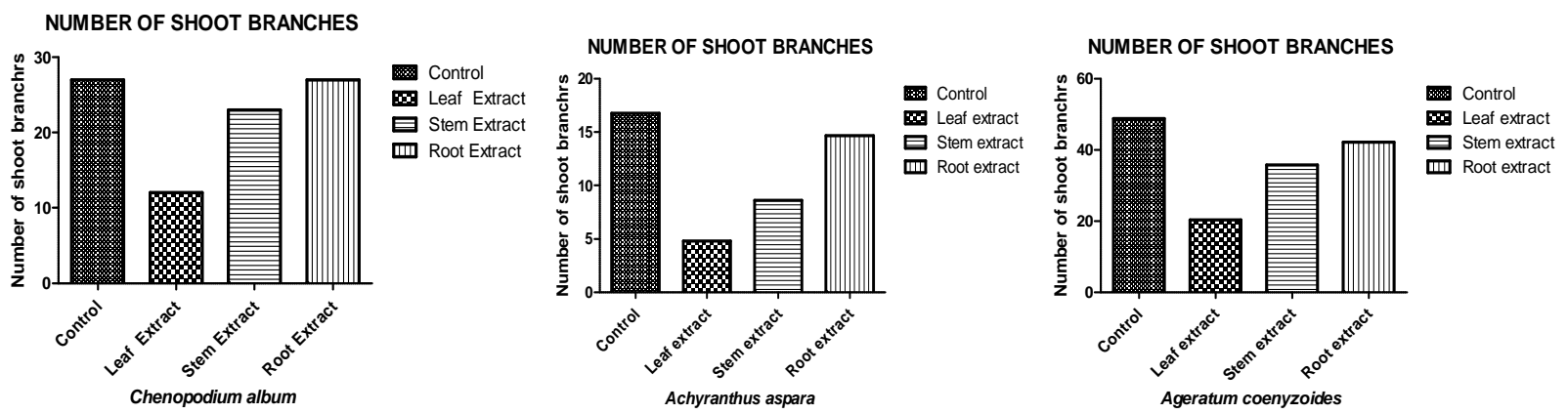

Fig. 14: Shows variation in no of shoot branches in seedling of different weeds Chenopodium album, Achyranthus asperaandAgeratum coenyzoides

\section{Number of root branches}

Mean values showed that seedlings of Chenopodium album treated with leaf extract (58\%) showed a minimum number of shoot branches than seedling treated with root extract $(78 \%)$ and stem extract $(85 \%)$ in comparison to control plants. Tukey's test of variance interpreted that a significant difference was shown between plants grown in control condition with the plants sprayed with leaf extract and stem extract.
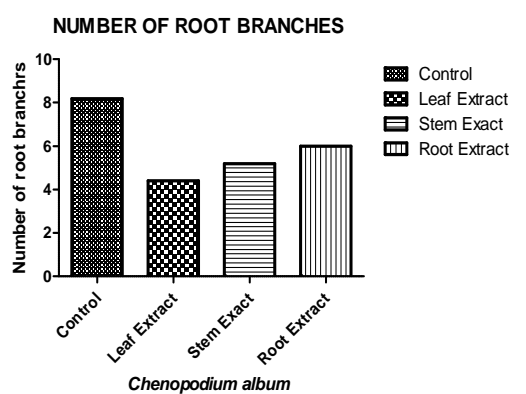

NUMBER OF ROOT BRANCHES

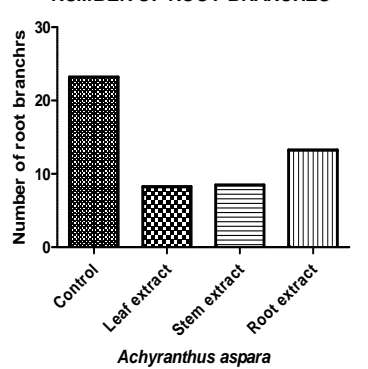

NUMBER OF ROOT BRANCHES
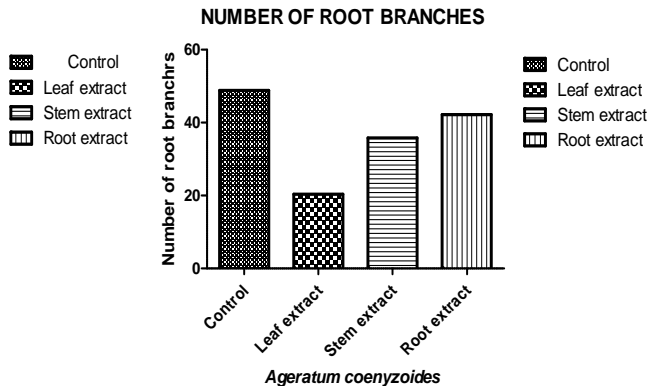

Fig. 15: It shows variation in no. of root branches in seedling of different weeds Chenopodium album, Achyranthus asperaandAgeratum coenyzoides

Effects of induction of leaf extract, stem extract, root extract and distilled water on the number of root branches were calculated after $60 \mathrm{~d}$ of treatment. It was evident from mean values that treatment with leaf extract (35\%) showed a minimum number of root branches than root extract (36\%) and stem extract (57\%) in comparison to control plants. Observation of a number of root branches in the extract treated seedlings of Ageratum coenyzoides showed that minimum reduction in the number of root branches was found in seedlings treated with leaf extract $(43 \%)$ in comparisons to control plants. However, a number of root branches differ in small quantity in plants treated stem extract (72\%) and root extract $(87 \%)$. It was interpreted from the table that a significant difference was shown between plants grown in control condition with the plants sprayed with leaf extract and root extract. A nonsignificant differences were found between controls vs stem extract; stem extract vs root extract.

\section{DISCUSSION}

Aqueous extracts of Withania somnifera exhibited phytotoxic activity against germination and early seedling growth of the noxious weeds, i.e., Chenopodium album, Achyranthus aspera and Ageratum coenyzoides. The leaf extract of Withania was comparatively more inhibitory to germination and seedling growth of the test weeds than corresponding stem and root extract in the laboratory and foliar spray bioassays.

Germination is the most critical stage in the establishment of weeds. Withania extract has shown a negative effect on the germination of studied weeds in the present investigation as leaf, stem and root extract has considerably suppressed the germination. The herbicidal role of medicinal plants was studied by various researchers. Inhibitory effect of Lantana camera extracts on germination of Eichhorn was studied [14]. The effects of Cassiatora and many other weeds on the germination, growth and metabolism of Parthenium hysterophorus was studied [15]. Among four weeds studied, many researchers have studied the effect of plant extract on Parthenium hysterophorus. Inhibition in the germination of Parthenium seeds by aqueous leaf extract of tree species i. e Azadirachta indica (L.). A. Juss., Ficus bengalensis L., and Melia azaduarachta L. were studied [16]. The inhibitory effects of Cassia on Parthenium hysterophorus 
and its suppression in nature were reported [17]. The herbicidal role of Avena viridis on Parthenium hysterophorus which helped in its management [15]. Reverse trend and indicated that Parthenium hysterophorus had a negative influence on different species of Cassia, through seed germination bioassay studies [18]. The negative effect of buckwheat on germination and growth of associated weeds. The extract of the plant could suppress the seed germination of weeds for a longer period, which might be due to chemical inhibitors or allelochemicals existing in them [19]. The results of present investigations are in agreement with the above findings as Withania somnifera possess a variety of allelochemicals in leaves, stem and roots.

In the present study, germination of all the studied weeds was effected by all the Withania extracts whereas leaf extract was more inhibitory. The greater inhibitory effect of aqueous extract of aerial parts on germination and growth of test species has also been reported in other plant species [20] and [21]. Effect of leaf extract was more inhibitory to germination and growth in Ageratum coenyzoides in comparison to other weeds. Leaf and stem extracts of Withania were more phytotoxic compared to root extracts. In Chenopodium album, Achyranthus aspera and Parthenium hysterophorus leaf affected stem length than root length whereas in Ageratum coenyzoides root length was inhibited to a greater extent by leaf extract. In laboratory bioassay, it was evident that minimum fresh weight was found in seedlings treated with leaf extract. The germination and seedling growth response of different weeds to aqueous extracts of Withania was different. This unequal susceptibility to weeds could be due to inherent differences in the phytochemicals involved in the process. The species specificity of phytotoxicity was demonstrated earlier [21, 22]). Leaf and stem extract of $W$. somnifera were more inhibitory to germination and seedling growth of studied weeds than root extract indicating that leaves and shoots contain more of an inhibitor than the roots. As stated earlier that phytochemicals like flavonoids, alkaloids, phytosterols, saponin, etc. were quantitatively different in different organs of Withania which could have a variable inhibitory effect on the seed germination.

Foliar spray bioassay on weeds seedlings also supported the earlier results in this field. The stem and root length of weeds were also negatively influenced by aqueous extracts of Withania. Leaf extract was more toxic to stem length than root length. Similarly, fresh weight and dry weight of seedling were severely influenced by leaf extract. Withania extract also reduced a number of shoot and root branches in all the studied weeds. Ageratum coenyzoides was more susceptive to Withania extract. Likewise studies on the effect of Withania somnifera on Rumex dentatus, Parthenium hysterophorus and Tagetes erectus $\mathrm{L}$ and found similar results as in the present study [23]. Similarly, Parthenium hysterophorus have provided very encouraging results. The effect of grasses on the germination ofParthenium hysterophorus as reported by [23] showed a reduction in seedlings root and shoot length and attributed it to reduce the rate of cell division and cell elongation due to the presence of allelochemicals in the aqueous extract [24]. Many seedlings lost their ability to develop normally as a result of reduced radical elongation and root nerosis [25].

Root growth was inhibited by aqueous extracts of many plants. Aqueous extracts of plants generally had a more pronounced effect on radicle growth than the hypocotyl growth [26]. This may be attributable to the fact that roots come in contact earlier with the extracted phytochemicals than the other organs of plants [27]. Root growth was more sensitive to the phytotoxin present in the aqueous sorghum and sunflower extract than was the shoot growth $[27,30]$. The greater inhibitory effect of aqueous exact of the aerial part on the germination and growth of the test species than the effect of sub aerial parts had also been reported in other plants [20].

\section{CONCLUSION}

The weeds studied are the prominent weeds of the mid-Himalayan region and he experiment revealed the fact that many medicinal plants can be used as a bioherbicide to control such weeds as well as invasive weeds. The phytochemical present in plants act as allelochemicals for the weeds and provide a safe and natural mean of weed management. Earlier initiatives have been proved successful, for examples, Artemisinin, a sesquiterpene lactone from the Artemisia annumL. is a patent plant growth inhibitor. Leptospernone is a known allelochemical from which the triketone class of herbicides was produced. Similarly, 1,8, coneole, a monoterpene, has been identified as one of the most potent allelochemical released by Artemisia spp. and a synthesise analog, cinmethylinia, being sold as a herbicide in Europe. As medicinal plants like Withania somnifera are a rich repository of phytochemicals and have a herbicidal effect over weeds, there is a possibility to commercialise its extracts as herbicide which will prove a milestone in the weed management in the Himalayan region.

\section{ACKNOWLEDGEMENT}

Authors are thankful to the faculty of Shoolini University of Biotechnology and Management Sciences, Solan for their suggestions and lab facilities.

\section{ABBREVIATION}

$\mathrm{W} / \mathrm{v}$ : weigh per volume,g: gram, FYM: farm yard manure, $\mathrm{kW}$ : kilowatt, C: control, L: leaf extract, R: root extract, S: stem extract.

\section{CONFLICT OF INTERESTS}

The authors have no potential conflict of interest regarding publication of the said manuscript

\section{REFERENCES}

1. Kabir M, Iqbal MZ, Shafiq M, Farooqi ZR. Effects of lead on seedling growth of Thespesia populnea. Plant Soil Environ 2010;56:194-9.

2. Lavin DA. The chemical defences of plants to the pathogens and herbivores. Annu Rev Ecol Evol Syst 1976;7:121-59.

3. Miri HR. Allelopathic potential of various plant species on Hordeum Spontaneum L. Adv Environ Biol 2011;5:3543-9.

4. Aldrich RJ. Weed-crop ecology, the principle in weed management. Breton Pub. North Scituate. Mass; 1984.

5. Baker HG. Characteristics and mode of origin of weeds. In Baker HG, Stebbins GL. The genetics of colonizing species. Academic Press: New York, USA; 1965. p. 147-72.

6. Baker HG. The continuing evolution of weeds. Ecol Bot 1991;45:445-9.

7. Holm LG, Plucknett DL, Pancho JV, Herberger JP. The World's Worst Weeds: Distribution and Biology. An East-West Centre Book University Press of Hawaii Honolulu, Hawaii; 1977. p. 609-11.

8. Duke JA. Promising phytomedicinal advances in new crops. Janick J, Simon JE. Editors. Timber Press Portland 1990;12:491-8.

9. McNeely JA. The great reshuffling: Human dimensions of invasive alien species. Ali Spec 2001;1:159-242.

10. Aper J. Seed germination and viability of herbicide resistant and susceptible Chenopodium. Weed Res 1998;32:219-42.

11. Neeta S, Uttamkumar B. Effect of Sulphaphenazole on pathogenic microorganism klebsiella aerogenes. Int J Biol 2011;2:106-10.

12. Kohli RK, Dogra KS, Batish DR, Singh HP. The impact of invasive plants on the structure and composition of the natural vegetation of north-western Indian Himalayas. Weed Technol 2004;18:1296-300.

13. Dogra KS. The impact of some invasive species on the structure and composition of the natural vegetation of Himachal Pradesh (PhD thesis). Panjab University, Chandigarh; 2008.

14. Zhang Z. Insights into the survival of chlamydomonas reinhardtii during sulfur starvation based on microarray analysis of gene expression. Eukaryot Cell 2004;3:1331-48.

15. Thapar R, Singh NB. Allelopathic effects of Amaranthus viridis on Partheniumhysterophorus. J Indian Bot Soc 2003;82:93-6.

16. Shafique S, Shafique S. Management of Parthenium hysterophorus $\mathrm{L}$. by a natural herbicide-Tagetes erectus $\mathrm{L}$. $3^{\text {rd }}$ International Symposium on Weeds and Invasive Plants in Ascona, Switzerland; 2011.

17. Tefera T. Allelopathic effects of Parthenium hysterophorus extracts on seed germination and seedling growth of Eragrostis tef. J Agron Crop Sci 2002;188:306-10. 
18. Rahman A. Allelopathic potential of Parthenium hysterophorus L. on Cassia sp. Allelo J 2006;18:345-55.

19. Chepil WS. Germination of weed seeds II. The influence of tillage treatment on germination. Sci Agric 1946b;26:347-57.

20. Kil B, Yun KW. Allelopathic effects of water extracts of Artemisia princeps on selected plant species. J Chem Ecol 1992;18:39-51.

21. Noor M, Khna MA. Allelopathic potential of Albizia samans. Pakistan J Bot 1994;26:139-47.

22. Shukla RS, Hussain A. Influence of various factor on toxicity of culture filtrate of a Drechslera maydis strain from Costus speciosus. J Phytopath 1987;118:187-92.

23. Javaid A, Anjum T, Bajwa R. Biological control of Parthenium II: Allelopathic effect of Desmostachya bipinnata on distribution and early seedling growth of Parthenium hysterophorus L. Int J Bioand Biotechnol 2005;2:459-63.

24. Duke SO, Dayan FE, Aliotta G, Oliva A, Romagni JG. Chemicals from nature for weed management. Weed Sci 2002;50:138-51.

25. Belal A, Ramady HR, Mohamed ES, Saleh AM. Drought risk assessment using remote sensing and GIS techniques. Arab J Geosci 2014;7:35-53.

26. Turk MA, Lee KD, Tawaha AM. Inhibitory effects of aqueous extracts of black must ard on germination and growth of radish. Res J Agric Biol Sci 2005;1:227-31.
27. Abdul BA, Hassan AM, Hassan AS. In vitro antimicrobial activity of Thymus vulgaris, Origanum vulgare and Rosmarinus officinalis against dental caries pathogens. J Pure Appl Sci 2012;25:1-7.

28. Niyati S Acharya, Jagruti J Patel. Phytochemical evaluation and in vitro antioxidant and anti-inflammatory effects of Clerodendrum serratum roots. Int J Pharm Pharm Sci 2016;8:158-63.

29. Krishnavignesh L, Mahalakshmipriya A, Ramesh M. In vitro analysis of phytochemical screening and antimicrobial activity of Parthenium hysterophorus l. against pathogenic microorganisms. Asian J Pharm Clin Res 2013;6:41-4.

30. Singh A, Uppala GK. A review on carissa carandas, phytochemistry, ethnol pharmacology, and micropropagation as conservation strategy. Asian J Pharm Clin Res 2015;8:26-30.

\section{How to cite this article}

- Mamta Sharma, Rupinder Kaur, Sunil Puri. Bio-herbicidal efficiency of withania somnifera against important himalayan weeds. Int J Pharm Pharm Sci 2017;9(3):88-97. 